\title{
How Zhu Shenghao the Translator of Shakespeare's Plays Influences and Inspires Chinese Undergraduates with His Red Boat Spirit
}

\author{
Jinhua Liu and Qingliang Meng
}

\begin{abstract}
The article first expounds the profound influence of Shakespeare's plays and the significance of translating them into Chinese. Then it introduces Zhu Shenghao's achievements and the origin and connotation of his "Red Boat Spirit". The three aspects of the "Red Boat Spirit", namely the pioneering spirit, the fighting spirit and the dedication spirit were found to match perfectly with what Zhu Shenghao displayed during his translation of Shakespeare's plays. Thereafter, the article illustrates the significance of setting up Zhu Shenghao as a moral example for contemporary college students before a final description of the concrete operation of integrating Zhu Shenghao into the education of college students' "Red Boat Spirit".
\end{abstract}

Keywords - Ideological education, Red Boat Spirit, Shakespeare, translation, University students, Zhu Shenghao.

\section{INTRODUCTION}

\section{A. The Influence of Shakespeare's Plays}

As one of the most outstanding English poets and playwrights during the European Renaissance, Shakespeare (1564-1616) wrote 37 plays in his lifetime besides poetry and is regarded as a treasure of world literature. For more than 400 years, Shakespeare's plays have exerted a wide and lasting influence not only on the world theater but also on human culture as a whole. According to Tian Yizhou [1], Shakespeare's works "have been playing a significant role in promoting human civilization". From the English poet Dryden to the French writer Hugo, from the Russian poet Pushkin, to the Chinese playwright Cao Yu, from the German poet Goethe to Karl Marx the thinker, all sing high praise of Shakespeare. Marx called him "one of mankind's greatest geniuses," and Jones thought Shakespeare "belonging not to one age, but to all centuries." Given the importance and influence of Shakespeare's plays in world history and culture, the translation of Shakespeare's plays into Chinese is a huge cultural project to enrich Chinese culture and promote exchanges between China and the West.

\section{B. The Translation of Shakespeare's Plays into Chinese}

The name "Shakespeare" did not appear in relevant Chinese literature until the middle of the 19th century. The Four Continent Chronicles compiled by Lin Zexu in the $20^{\text {th }}$ year of Period of Emperor Daoguang (1840) in the Qing Dynasty mentioned that "Shakespeare" and other writers from Britain "wrote a lot of poems and writings" [2]. In 1856,

Published on September 08, 2021

Jinhua Liu, BE191, Department of English Language, Pinghu Teachers' College, Jiaxing University, Jiaxing, P.R. China. the sixth year of Xianfeng Emperor Period, in the Chinese version of the Great Britain Chronicles translated by William Mooch a British missionary working for Mohai Academy in Shanghai, the name "Shakespeare" was also mentioned [3]. Later, Liang Qichao a thinker of the modern period and one of the leaders of the Reform Movement of 1898 mentioned in his Poems of the Iced Tea House (1902) that the poems of "modern poets" such as Shakespeare "have great verve", which is really "grand!" (ibid.). Before and after the May 4th Movement, more Shakespeare's works were translated into China, but most of them were based on half or a part of one play. For example, in 1921, the famous playwriter Tian Han translated "Hamlet" in vernacular Chinese, which was published on the magazine "Young China". As an enduring literary classic, there was an urgent need for an accurate, elegant, and excellent translation of Shakespeare's plays. This great historical responsibility fell on the young Zhu Shenghao (1912-1944).

The article first expounds the profound influence of Shakespeare's plays and the significance of translating them into Chinese. Then it introduces Zhu Shenghao's achievements and the origin and connotation of his "Red Boat Spirit". The three aspects of the "Red Boat Spirit", namely the pioneering spirit, the fighting spirit and the dedication spirit were found to match perfectly with what Zhu Shenghao displayed during his translation of Shakespeare's plays. Thereafter, the article illustrates the significance of setting up Zhu Shenghao as a moral example for contemporary college students before a final description of the concrete operation of integrating Zhu Shenghao into the education of college students" "Red Boat Spirit".

\section{ZHU SHENGHAO'S TRANSLATION OF SHAKESPEARE PLAYS AND THE ORIGIN OF RED BOAT SPIRIT}

A. Zhu Shenghao's Achievements in Translating Shakespeare Plays

Zhu Shenghao, a native of Jiaxing, is undoubtedly one of the most well-known translators of Shakespeare's plays into Chinese. Among the numerous translations of Shakespeare's plays, The Complete Works of Shakespeare translated by Zhu Shenghao has won "extensive praise and recognition" [4], and it still shines through the test of the times. Many classic sentences have already become popular and widely circulated. After comparing several versions of The Merchant

Qingliang Meng, Department of English Language, Pinghu Teachers' College, Jiaxing University, Jiaxing, P.R. China.

(corresponding author: mikemeng@163.com) 
of Venice, Fang Ping the scholar said, "In terms of the appropriateness and fluency of the text, Zhu's version should come first." Zhu Shenghao stood out from many translators of Shakespeare's plays and was gradually recognized as one of the most outstanding translators of Shakespeare's plays and the first translator of Shakespeare's plays. Cao $\mathrm{Yu}$, a master of drama and the first president of China Shakespeare Society, wrote an inscription in his own hand, praising his "remarkable achievements" in his life. However, the birth of Zhu Shenghao's version of Shakespeare's classic plays were not a smooth sailing but went through hardships and even the cost of life. Zhu Shenghao embodies the spirit of the contemporary Red Boat. This spirit supported him to overcome difficulties and complete the project with high quality. His classic translations have been read, appreciated, and disseminated by generation after generation, becoming a part of Chinese culture and a precious spiritual treasure.2.2 The origin of Red Boat spirit and its content

In July 1921, the Communist Party of China held the first National Congress in Shanghai. However, because of the harassment from the police patrol of the French Concession, it was forced to transfer to a small cruise boat on the South Lake of Jiaxing, Zhejiang province. Finally, it was on this boat that the Communist Party of China declared its founding and adopted its first program, resolution, and declaration, which set out the Party's goals, tasks and work to be carried out. The birth of the Communist Party of China marked that the ship of the Chinese revolution set sail from here, reflecting the pioneering spirit of "making the world and daring to be the first". In the following decades, the Communist Party of China led the people of the whole country with "indomitable and firm ideals" to win the victory of the revolution. Since the founding of the People's Republic of China, the party has been still working for the welfare of the people wholeheartedly, which embodies the dedication spirit of "building the Party for the public and being loyal to the people". On June 21, 2005, General Secretary Xi Jinping published a signed article on Guangming Daily entitled "Carry Forward the Spirit of the Red Boat", which put forward and systematically expounded the "Red Boat Spirit" for the first time. The "Red Boat Spirit" is the source of the Chinese revolutionary spirit. It refers to the pioneering spirit daring to be the first, the spirit of steadfast ideals and indomitable struggle, and the dedication spirit of building the Party for the public and being loyal to the people.

Zhu Shenghao, who was born nearby the South Lake in Jiaxing, may have never been on the boat. Nevertheless, immersed in the traditional Chinese culture since his childhood, he was like any residents of Jiaxing who had never given up easily in the face of difficulties and hardships. This had encouraged to be determined to do something in the future when he still was young. A careful study of the connotation of the spirit of the Red Boat, combined with the difficult process of Zhu Shenghao's translation of Shakespeare's plays, reveals that Zhu Shenghao embodies three aspects of the spirit of the Red Boat and is a model for contemporary college students to learn from.

\section{THE PERFECT MATCH BETWEEN ZHU SHENGHAO AND RED BOAT SPIRIT}

\section{A. Pioneering Spirit}

At the beginning of the 20th century, with the decline and disintegration of the Qing Dynasty and the further spread of Western learning to the East, some advanced Chinese intellectuals launched a new cultural movement against feudalism. Meanwhile Shakespeare's plays contain profound and rich humanism ideals, which are fresher and more attractive than traditional Chinese literature and opera and are thus more likely to arouse the resonance of the intellectuals. In this context, Tian Han, Liang Qichao, and other famous scholars successively translated and introduced Shakespeare's plays. However, as there are more than 37 plays written by Shakespeare, there was no systematic and complete translation of Shakespeare's plays into Chinese at this time. After translating Gogol's Dead Souls, Lu Xun wrote three articles on Shakespeare in succession, thinking that this was a world-famous masterpiece and hoping that someone could complete the translation of Shakespeare's plays. Zhu Shenghao, an editor of the World Book Company, accepted the commission of Zhan Wenhu, the chief editor of the English and Chinese four-use Dictionary, and began preparation for the translation of the complete plays of Shakespeare. The reason why Zhu Shenghao dared to undertake such a difficult task was not only his full confidence in his English and Chinese proficiency, but also his pioneering spirit. In a 1936 letter to his wife Song Qingru, he wrote:

But what I value most, and what I am most willing to devote all my energy to, is the third volume, which is by far the longest, the whole of the historical plays of England. It is not because it is more valuable than the various masterpieces of comedy and tragedy, but because it has never been introduced into China. ... But for all the talk of Shakespeare and Hamlet in China, few people know this equally great name. [5, p.108]

From this perspective, the reason why Zhu Shenghao agreed to translate the Complete Works of Shakespeare's Plays is that, apart from his admiration for Shakespeare's plays and their own value, the more important reason lies in the fact that "Shakespeare has never been introduced into China". This is the concrete embodiment of his pioneering spirit and courage.

\section{B. Struggling Spirit}

In the $2^{\text {nd }}$ half of Gaozi of Mencius, it said "Therefore, the heaven will be a great responsibility, so people also, must first suffer their mind and will, strain their bones and muscles, starve their body and skin, empty their body, do what they do, so move their heart and endure, once they cannot benefit." This is especially true of Zhu Shenghao. In the most difficult ten years before and after the Anti-Japanese War, he endured the hardships of poverty and illness, and with extraordinary perseverance, "completed a difficult project for the cultural cause of China for nearly one hundred years" [6]. China in the 1930s was in the period of the New Democratic Revolution, when warlords were fighting, and the situation was turbulent. After the September 18 Incident, Japan plotted 
the "Lugou Bridge Incident" in 1937 and comprehensively invaded China. The eight-year Anti-Japanese War began. During the days of tension and artillery fire, the Japanese often broke into newspaper offices to search for progressives, anti-Japanese books, and newspapers. Some of the comic manuscripts translated by Zhu Shenghao were destroyed by gunfire after they were handed over to the book office. Later on, some of them were translated in the migration period and in the Sino-American Daily Library. However, these manuscripts became burial objects when the newspaper office was occupied. In such a dangerous situation, Zhu lived a "quiet life, full of grief, humiliation and longing, with violent aggression outside the door and wolves followed by a pack of shameless cheap dogs." He often had to flee from Shanghai and returned to Jiaxing to escapethe search and war, leading a vagrant life. In the winter of 1938 , he spent a winter in Xincheng of Jiaxing. Later with the approach of the Japanese invaders, he had to flee again to the town of Xinshi, a place full of water. During the migration, Zhu took only two dictionaries and the complete works of Shakespeare with him, but as soon as he settled down and found a place to put the books, he immediately immersed himself in translation and writing to continue his work. During these ten years, Zhu Shenghao endured the predicament of "poverty, disease and mutual distress" [5]. He worked diligently to overcome the difficulties and completed the translation of 31 of Shakespeare's 37 plays after ten years of work. The reason why he could persevere and persist in the translation work is that he had the same struggling spirit of "firm ideal and indomitable" as the Chinese revolution.

\section{Dedication Spirit}

Hard work and poverty were eroding Zhu's health. By the second half of 1943, he had abdominal pain. His teeth ached one after another, but he paid no attention to it and continued to work despite the pain. He described his experience in the Translator's Preface in The Complete Works of Shakespeare's Plays as follows:

I am fond of Shakespeare's play very much. I've studied it at least a dozen times. I think I have a good understanding of the spirit of the original work. In the spring of the fourth year, with the encouragement of Mr. Zhan, a senior colleague, I began to try to translate the complete works. During the war broke out the next year, all my collection of Shakespeare's works, including more than one or two hundred editions with annotations, translation and comments by various scholars, were ruined by gunfires. In a hurry, I only brought out a complete Edition of Oxford Dictionary and several translated copies. Later, I wandered around for life, and had no spare time to continue the unfulfilled wishes. In the spring of 1931, I saw that the world was becoming more and more urgent. I stayed at home behind closed doors and refused foreign affairs. I began to get an idea and try my best to translate things. Although I was poor and ill, which frequently occur at the same time, I tried my best to bury myself in the table and continued translation. After ten years, the whole manuscript was completed. Due to the arduousness of the translation work, ten years of work can not be said to be a long time, but I had dedicated my whole life to this project.
In this preface, Zhu Shenghao first told the reason why he undertook the project commissioned by Zhan Wenhu. And the reasons for his daring to take on such an important task lie in his full confidence and adequate preparation. Under the circumstances it was difficult for him to settle down and concentrate on the work. But he succeeded in translating the majority of Shakespeare's 37 plays out of his love for Shakespeare's plays, his great ideal, his determination to overcome difficulties and obstacles, his unswerving spirit. He had devoted all his energy even his young life to the completion of this great feat. Since its founding, the Communist Party of China (CPC) has been "building the Party for the public and governing for the people". In leading the Chinese people in the struggle to achieve national independence and prosperity, countless Party members and people with lofty ideals have also laid down their lives. With his wisdom, efforts and life, Zhu Shenghao has filled a big gap in Chinese translation field and made outstanding contributions to the cultural cause of the Chinese nation. He also embodies the dedication spirit of the "Red Boat Spirit".

The spirit shown by Zhu Shenghao in the process of translation coincides with the connotation of "Red Boat Spirit". The times are changing, and the society is progressing. However, the pioneering spirit of "pioneering the world and daring to be the first", the fighting spirit of "firm and indomitable ideals" and the dedication spirit of "building the Party for the public and governing for the people" are the same as the Chinese nation's hard struggle and indomitable spirit and will never be out of date. It is with the support of this spirit that the Chinese nation has stood firm among the nations of the world despite all difficulties and hardships. Contemporary college and university students, who will be the mainstay of China in the coming decades, should also have the "Red Boat Spirit" like Zhu Shenghao. However, today's college students, most of whom were born after the millennium, lead a prosperous life compared with their predecessors. Growing up with electronic products, many of them have never experienced hardships and difficulties, and generally lack lofty ideals and indomitable perseverance. Therefore, publicizing Zhu Shenghao's story among students not limited to English majors, appreciating the beauty of Zhu's classic translations, and making them aware of the great perseverance of this great translator will help arouse their sympathy, cultivate, and strengthen their character and will.

\section{THE SPIRITUAL OUTLOOK OF CONTEMPORARY UNDERGRADUATES}

Zhao Ping [7] summarizes the volition quality of contemporary undergraduates into three aspects: goal loss and self-confusion; lack of perseverance; weak psychological endurance, unable to put up with setbacks. Li Shuhong[8] summarizes it into five aspects: (1) unsteady willpower, namely, they tend to be indecisive, rash, and arbitrary at key points in the process of striving to achieve their goals. (2) imbalance of development, which is mainly manifested as poor persistence, obvious inertia, and lack of perseverance when the purpose and consciousness of behavior are significantly improved. (3) great individual differences in the level of volition. Some college students are weak in volition 
and cannot face up to difficulties. (4) weak in tolerating frustration and coping hardships, leading to a strong stress response after setbacks, abnormal emotional excitement and even aggressive behavior. (5) obvious insufficiency in exercise and cultivation of willpower. The conclusion of the two scholars basically summarizes the current situation of the volitional quality of contemporary college students. In recent years, high school students, college students and even graduate students have been repeatedly reported to resort to extreme behavior due to academic pressure, criticism from partents or teachers, or emotional frustration, indicating that the problem is not easing, but is getting worse.

On the other hand, China's rapid economic development in the past few decades has greatly enhanced its comprehensive strength and increased its international influence, which has aroused the concern and vigilance of Western capitalist countries led by the United States, who have been making every effort to obstruct and contain it. For example, the US is not only fighting a trade war with China, but also suppressing and blocking China in terms of technology. Under such circumstances, for the great rejuvenation of the Chinese nation, college students in particular need the pioneering spirit. In the past 100 years since the founding of the Communist Party of China (CPC), the path of leading the Chinese people to achieve independence and prosperity has not been plain sailing. The road to national rejuvenation will be fraught with difficulties and obstacles as well. Therefore, there is an urgent need for college students to cultivate the "firm and indomitable ideal" spirit of struggle, which is not only the requirements of the country and society for the youth, but also conducive to the physical and mental health of college students. In addition, with the popularity of smart phones, the development of the Internet, especially the proliferation of "We Media" in recent years, some college students are addicted to games or entertainment, or obsessed with ease and pleasure, and lack the determination and perseverance to deal with difficulties and setbacks. Therefore, it is urgent to carry out ideological and moral education to college students through "Red Boat Spirit" and advocate the spirit of struggle and dedication. In this regard, Zhu Shenghao is an ideal and excellent example of inspiration.

\section{InTEgrating Zhu Shenghao CASE INTO Red BoAT SPIRITUAL EDUCATION}

\section{A. Red Boat Spirit Ideological Education Case}

Zhu Shenghao, a native of Jiaxing, was born and brought up near the South Lake. Carrying the "spirit of the Red Boat," the Red Boat is a cruise boat on the South Lake, the second venue for the first national congress of the Communist Party of China. Zou Pei and Huang Delin [9] proposed a path to cultivate advanced models of college students through "Red Boat Spirit", which is to "lead young college students to enhance their sense of mission and responsibility to contribute to the people, society and the motherland with real, touching and advanced typical deeds, and spread positive attitudes". Li Shuhong [8] made use of the power of example as one of the strategies for cultivating college students' willpower. Because the role model on the will of the action of the people's inspiration, "cannot be replaced by any other means." Zhu Shenghao is such a typical example. "Red Boat Spirit" mainly refers to the initiative, struggle and dedication spirit of the Communist Party of China, and Zhu Shenghao's translation work also reflects his pioneering courage, indomitable perseverance, and selfless dedication to the cultural cause. In view of the high agreement between the two, Zhu Shenghao can be taken as a typical case to study in the education of college students with "Red Boat Spirit."

\section{B. Syllabus Ideological Teaching Case}

For English majors, it is necessary to know Zhu Shenghao. Shakespeare's plays are the Canon of English literature. From Hamlet to Romeo and Juliet to the better known The Merchant of Venice, students can not only feel and appreciate the charm of the English language, but also understand the philosophy and humanism conveyed by the clever words and expressions. Through Zhu Shenghao's translation, students can feel the extensive and profound Chinese and superb expressions. Take for example the classic scene at the beginning of Hamlet:

To be, or not to be: that is the question:

Whether 'tis nobler in the mind to suffer

The slings and arrows of outrageous fortune,

Or to take arms against a sea of troubles,

And by opposing end them?

Comparing several translations, we can find that Zhu Shenghao's translation is superior. His translation reads like this:

\section{生存还是毁灭，这是一个值得考虑的问题；}

shēng cún hái shi huǐ miè, zhè shi yí gè zhí dé kăo lü de wèn tí;

\section{默然忍受命运暴虐的毒箭，}

mò rán rěn shòu mìng yùn bào nüè de dú jiàn, 或是挺身反抗人世无涯的苦难，

huò shì tǐng shēn fãn kàng rén shì wú yá de kǔ nàn, 通过斗争把它们清扫,

tōng guò dòu zhēng bă tā men săo qīng, 这两种行为, 哪一种更高贵?

Zhè liăng zhǒng xíng wéi, nă yī zhǒng gèng wéi gāo guì? In addition, such classic lines as “宇宙的精华，万物的灵 长” (yǔ zhòu de jīng huá, wàn wù de líng zhăng) with the source text as "the essence of the universe, the soul of all things" were also produced by Zhu Shenghao.

The teacher can share with students the process of Zhu Shenghao's translation of such classic lines of Shakespeare, whether during the appreciation of the charm of the original text or the explanation of translation strategies. At such moments, efforts can be made to combine Zhu Shenghao's qualities with the three aspects of the "Red Boat Spirit". Through Zhu Shenghao's classic translation, we seem to feel or to see his thin figure but resolute eyes, his noble soul and indomitable spirit. It is believed that these would inspire the students to be brave, to persevere when encountering difficulties of various kinds, being determined to pursue excellence. 


\section{ACKNOWLEDGEMENT}

This research was supported by the student SRT project of Jiaxing University (Jiaxing, China) (Project No.: CD8517204010).

\section{REFERENCES}

[1] T. Yizhou, "A Discussion of the Influence of Shakespeare's Plays." Drama Periodicals (3), 2007.

[2] Z. Man, "Lin Zexu Si Zhou Chronicles." Beijing Huaxia Publishing House, 2002

[3] G. Baoquan, "Romain Rolland and China.” French Studies (04), 1986.

[4] L. Weimin, "Three Questions Regarding the Translation and Introduction of Shakespeare's Plays." Journal of Anhui Normal University (Humanities and Societies) (6), 2006.

[5] S. Qingru, "Zhu Shenghao and Shakespeare' Plays." New Literary Historical Materials (01), 1989.

[6] Z. Hongda, W. Jiemin, "Thoughts and Achievements of Zhu Shenghao's Translation of Shakespeare's Plays." Journal of Jiaxing University (5), 2005.

[7] Z. Ping "Current Status of the Volitional Qualities of Contemporary University Students and Countermeasures." Journal of Shaoguan College (Social Science) (11), 2014

[8] L. Shuhong, "Volitional Qualities of Contemporary University Students and Cultivation Strategies." Educational Exploration (5), 2013.

[9] Z. Pei, H. Delin "Path Exploration of Models in Cultivating Excellent Undergraduates through Red Boat Spirit." Party Building and Ideological Education at Schools (Higher Education Edition) (01), 2020. 